\title{
A utilização da fotografia como fonte de pesquisa em estudos históricos sobre a enfermagem
}

\author{
The use of photography as a research source on historical studies on nursing \\ El uso de la fotografía como fuente de investigación en estudios históricos de enfermería
}

\section{Resumo}

Introdução: o estudo teve como objetivo analisar a produção científica referente à história da Enfermagem tendo como fonte de pesquisa a fotografia. Metodologia: realizou-se a revisão integrativa na literatura cinza e no Portal da Biblioteca Virtual em Saúde, onde foram selecionados oito artigos nas bases de dados SciELO, LILACS, BDENF e MEDLINE. Resultado: há evidência de que a totalidade dos artigos é de autoria de enfermeiros brasileiros, na temática Segunda Guerra Mundial, em cinco dos oito artigos. Ressalta-se que os autores estão presentes em mais de um desses cinco artigos, em especial, os oriundos do Rio de Janeiro. A abordagem mais frequente encontrada é a sócio-histórica, tendo um ponto em comum, que é a articulação entre a fotografia e outras fontes de estudo, tais como o uso de documentação histórica para ratificar o contexto e o conteúdo da imagem. Conclusão: o uso da fotografia evidenciou a visão que a sociedade tem sobre a Enfermagem, bem como deixou claro que a História da Enfermagem deve ser explorada com novos estudos e integrantes. Para tal, devem-se possuir investimentos para que a pesquisa histórica utilize diferentes fontes, inclusive, o uso da fotografia, pois, assim, haverá o aproveitamento do conhecimento, que é construído por fundamentos, e uma maior exploração possível.

Palavras-chave: Enfermagem; História da enfermagem; Fotografia.

\begin{abstract}
Introduction: The study aimed to analyze the scientific production related to nursing history having the photograph as a research source. Methodology: An integrative review was carried out in the gray literature and in the Virtual Health Library Portal, where eight articles were selected from the databases SCIELO, LILACS, BDENF and MEDLINE. Results: There is evidence that all articles are authored by Brazilian nurses on the theme of the Second World War, present in five of the eight articles. It should be noted that the authors are present in more than one of these five articles, especially those from Rio de Janeiro; The most frequent approach found is the socio-historical
\end{abstract}


approach having one point in common, which is the articulation between photography and other sources of study, such as the use of historical documentation to ratify the context and content of the image. Conclusion: The use of photography evidenced the view that society has about nursing, as well as, made it clear that the Nursing History must be explored with new studies and members. To this end, investments must be made for historical research to use different sources, including the use of photography, as this way, there will be the use of knowledge, which is built on fundamentals and as much exploration as possible.

Keywords: Nursing; Nursing history; Photography.

\section{Resumen}

Introducción: El estudio tuvo como objetivo analisar la producción científica referente a la historia de la enfermería teniendo la fotografia como fuente de investigación. Metodología: Se realizó revisión integrativa en la literatura gris y en el Portal de la Biblioteca Virtual en Salud, donde fueron seleccionados ocho artículos en las bases de datos SCIELO, LILACS, BDENF y MEDLINE. Resultados: Hay evidencia que la totalidad de los artículos tiene como autores enfermeros brasileños y en cinco de los ocho artículos el tema es Segunda Guerra Mundial. Se resalta que los autores están presentes en más de uno de eses cinco artículos, en especial los que son oriundos de Rio de Janeiro. El abordaje frecuente más encontrado es el sociohistórico, lo que representa un punto en comum, existe articulación entre la fotografia y otras fuentes de estudio, tales como, el uso de documentación histórica para ratificar el contexto y el contenido de la imagem. Conclusión: El uso de la fotografia há evidenciado la visión que la sociedad tiene sobre la enfermería, así como, dejó claro que la Historia de la Enfermería debe ser explorada con nuevos estudios e integrantes. En ese sentido debe existir inversiones para que la investigación histórica utilize diferentes fuentes, inclusive el uso de la fotografia, pues así, podrá aprovecharse el conocimiento, que es construído por fundamentos y con más exploración posible.

Palabras clave: Enfermería; História de la enfermería; Fotografia.

\section{Introdução}

Este estudo possui, como temática, a utilização da fotografia como fonte de pesquisa na História da Enfermagem evidenciada nas produções científicas. A fotografia teve seu uso no início da década de 1860, período denominado de revolução industrial, época de grandes avanços da ciência, quando os fatos do passado, como hábitos, religião, monumentos e comemorações, passaram a ser registrados e documentados por fotografias. O mundo tornou-se, assim, portátil e ilustrado (Kossoy, 2001).

Na pesquisa histórica, os estudiosos vêm utilizando diversas fontes, dentre elas, as orais, documentais e iconográficas, a saber: fotografia; filmes; roupas; pinturas; anúncios publicitários; artefatos e pessoas históricas (Padilha, Bellaguarda, Nelson, Maia \& Costa, 2017). Trata-se, neste estudo, em especial, da utilização da imagem fotográfica.

A fotografia ganha destaque dentre as fontes de pesquisa por ser utilizada pelos pesquisadores da Enfermagem, principalmente em estudos cujo assunto é a identidade profissional. Eles desvelaram indumentárias, posturas, gestos e representatividade. Com isso, comumente, a fotografia necessita da utilização de outras fontes para complementação, ou seja, necessita de grande apego textual devido à dificuldade de pesquisar, além de diversas interpretações geradas por pesquisadores com formações diferenciadas e com entendimentos singulares da imagem analisada (Padilha, Bellaguarda, Nelson, Maia \& Costa, 2017).

Nesse contexto, pode-se revelar que a memória, a lembrança e a fotografia estão intimamente entrelaçadas. A memória é a capacidade de manter informações do passado em um conjunto de funções psíquicas e a lembrança é a essência da memória.

Dessa maneira, a fotografia, seja de um único indivíduo ou do coletivo, permite relembrar momentos do passado, como, também, ter informações de momentos vividos por outras pessoas (Felizardo \& Samain, 2007).

Ressalta-se que a fotografia é de extrema importância para resgatar e construir memórias. Desse modo, o registro das imagens tornou-se mais fácil com o avanço da tecnologia do que anteriormente. Isto se dá pela facilidade e pela possibilidade de a maioria dos indivíduos possuir dispositivos móveis com câmeras e resoluções que tornam a imagem cada vez mais próxima da realidade, o que estimula a divulgação nas redes sociais e nos veículos de informação digitais.

O registro frequente dos momentos vivenciados e presenciados dos indivíduos, das famílias e da sociedade é decorrente da facilidade do acesso e do manejo da rede social. Outro fator a ser considerado é o valor de venda dos dispositivos 
fotográficos, que os torna cada vez mais acessíveis, facilitando a aquisição por parte da população. Contudo, é preciso refletir sobre o registro das imagens. As fotos digitais são registradas excessivamente, sem critérios de armazenamento, o que leva à banalização dessas imagens. Tais dispositivos tornam o indivíduo refém das memórias "RAM" e, quando estas se esgotam, temse o poder de apagar as imagens que perderam o encanto e o interesse, o que leva à perda da memória nelas contida (Felizardo \& Samain, 2007). Por isso, para preservar a memória da sociedade, é preciso que os acervos iconográficos mantenham a coleta e a categorização do material.

Na Enfermagem, percebe-se que paulatinamente surgem estudos com a utilização da fotografia como fonte histórica e os pesquisadores têm se empoderado dessa fonte rica em detalhes do passado. Apesar disso, há a preocupação desses pesquisadores em preservar documentos e fotografias em vários centros que resgatam a memória da Enfermagem. Nesse sentido, destacam-se o Centro de Memória Nalva Pereira Caldas, criado em 18 de junho de 1998, na Faculdade de Enfermagem da Universidade do Estado do Rio de Janeiro, com 6.679 fotografias nos meios físico e digital; o Museu da Escola de Enfermagem Anna Nery (EEAN), inaugurado no dia 22 de maio de 2017, que possui acervo datado desde a década de 1920 (TIC/UFRJ, 2017); a Escola de Enfermagem de Ribeirão Preto (EERP), fundada em 9 de maio de 1989, que tem, em seu arquivo iconográfico, aproximadamente 15 mil fotografias em suporte de papel e 4.116 fotos digitalizadas, além de outros arquivos como o museológico, o documental e textual e os arquivos sonoros (EERP, 2020).

Frente a essa conjuntura, o estudo mostra-se relevante em evidenciar o uso da fotografia como fonte de pesquisas históricas na área da Enfermagem, configurando-se em mais um recurso para o pesquisador analisar seus dados. Com essas considerações, apresenta-se o seguinte objetivo: analisar a produção científica referente à História da Enfermagem tendo como fonte de pesquisa a fotografia.

\section{Metodologia}

Trata-se de um estudo de abordagem qualitativa, realizado por meio da revisão integrativa de publicações que versam sobre a utilização da fotografia como fonte de pesquisa na História da Enfermagem. A revisão integrativa é uma modalidade de revisão sistemática que reúne estudos com o mesmo assunto para a identificação e posterior análise dos conteúdos existentes na literatura. Divide-se em seis etapas: elaboração da pergunta norteadora; busca das pesquisas ou amostragem na literatura; coleta de dados; análise crítica dos estudos incluídos; discussão dos resultados e apresentação da revisão integrativa (Souza, Silva \& Carvalho, 2010).

Posto isso, a questão norteadora que guiou este estudo foi: "Como a utilização da fotografia pelos enfermeiros é evidenciada na produção científica sobre a História da Enfermagem?”.

A busca dos estudos foi realizada no ano de 2020, no Portal da Biblioteca Virtual em Saúde (BVS), com os Descritores em Ciências da Saúde (DeCS): Enfermagem; história da Enfermagem e fotografia. Usou-se o operador booleano “and” para o cruzamento dos descritores a fim de obter o maior número possível de estudos que respondessem à questão proposta nas bases de dados: Scientific Electronic Library Online (SciELO); Literatura Latino-americana e do Caribe em Ciências da Saúde (LILACS); Banco de Dados em Enfermagem (BDENF); National Library of Medicine (MEDLINE) e na literatura cinza, isto é, no Google Acadêmico.

Os critérios de inclusão foram os artigos científicos completos e disponíveis on-line, textos nos idiomas português, espanhol e inglês e que abordavam o uso da fotografia e de fac-símiles de fotografia como fonte histórica para estudos em História da Enfermagem. Não houve delimitação de recorte temporal, o que permitiu incluir todos os artigos disponíveis encontrados até aquele momento, independentemente do ano de publicação. Os critérios de exclusão foram teses, dissertações e artigos repetidos em mais de uma base de dados. 
Inicialmente, realizou-se a leitura dos títulos. Na sequência, fez-se a leitura dos resumos de modo a pré-selecionar os artigos em conformidade aos critérios de inclusão. Posteriormente, fez-se a leitura na íntegra destes artigos com o objetivo de constituir a amostra final. Segue graficamente, representado no fluxograma 1, o caminho percorrido para a seleção dos artigos elegíveis para o estudo.

Fluxograma 1: Seleção dos artigos por bases de dados com a utilização do fluxograma PRISMA. Rio de Janeiro, RJ, Brasil, 2020 .

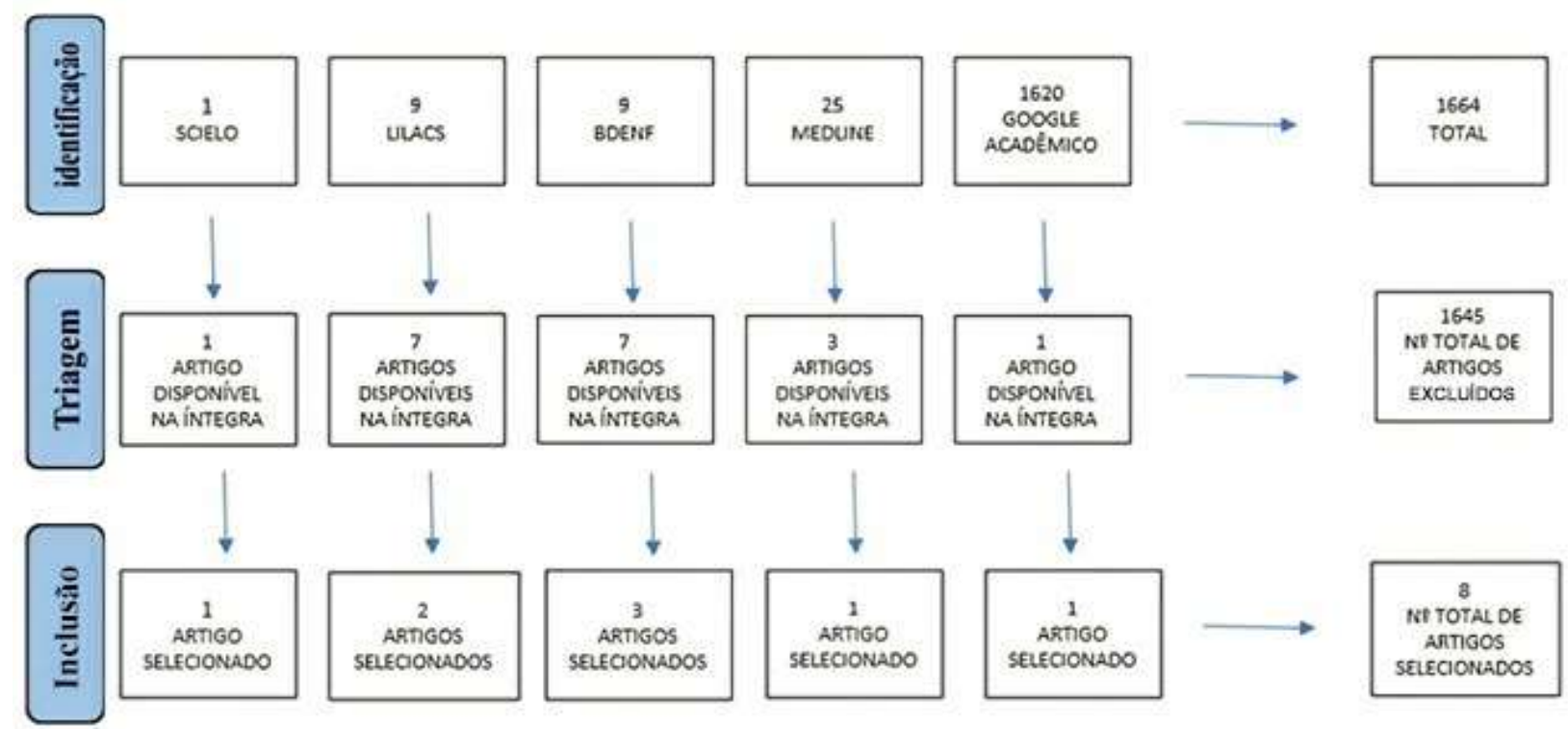

Fonte: Autores (2020).

No fluxograma 1, observa-se que, na BVS, há 43 publicações e, no Google Acadêmico, 1.620, o que perfaz o total de 1.664. Contudo, após a aplicação dos critérios de inclusão, na BVS, ficaram sete artigos e, no Google Acadêmico, um, o que resultou em oito artigos selecionados e 1.645 publicações refutadas.

Observa-se que, na LILACS, nove artigos foram encontrados, sendo sete refutados por não atenderem aos critérios de inclusão, o que acarretou a seleção de dois artigos científicos; na BDENF, constavam nove artigos, mas seis não atendiam aos critérios de inclusão, sendo três selecionados; na MEDLINE, foram encontrados 25 artigos, porém, 24 não atendiam aos critérios, restando um; na SciELO, foi encontrado um estudo que atendia aos critérios de inclusão; no Google Acadêmico, foram exibidas 1620 publicações, das quais 1.619 foram excluídas e apenas uma atendia aos critérios de inclusão. Ao final, foram selecionados oito artigos científicos.

Quadro 1: Apresentação dos artigos segundo o ano e o título. Rio de Janeiro, RJ, Brasil, 2020.

\begin{tabular}{|c|c|}
\hline Ano de publicação & Título \\
\hline 2005 & $\begin{array}{c}\text { A visibilidade da atuação de uma enfermeira do Exército Brasileiro a um ferido } \\
\text { na } 2^{\text {a }} \text { Guerra Mundial }\end{array}$ \\
\hline 2005 & $\begin{array}{c}\text { Base de sustentação militar de Vargas durante a 2 }{ }^{\text {a }} \text { guerra e a soberania bélica } \\
\text { alemã: percepções de enfermeiras e militares }\end{array}$ \\
\hline 2007 & $\begin{array}{c}\text { Enfermeiras do Exército Brasileiro no transporte aéreo de feridos: um desafio } \\
\text { enfrentado na 2 }{ }^{\text {a }} \text { Guerra Mundial }\end{array}$ \\
\hline 2009 & $\begin{array}{c}\text { Enfermeiras brasileiras na retaguarda da segunda guerra mundial: repercussões } \\
\text { dessa participação }\end{array}$ \\
\hline
\end{tabular}




\begin{tabular}{|c|c|}
\hline 2010 & $\begin{array}{l}\text { Condecorações de guerra como investidura de bens simbólicos às ex-enfermeiras } \\
\text { febianas }\end{array}$ \\
\hline 2012 & Aplicação da semiótica na análise de fac-símiles: pesquisa documental \\
\hline 2012 & Aparelhagem da imagem pública da enfermeira na revista Fon-Fon \\
\hline 2018 & $\begin{array}{c}\text { Maria José de Oliveira: trajetória de vida e contribuições para a construção da } \\
\text { identidade profissional da enfermeira na Bahia }\end{array}$ \\
\hline
\end{tabular}

Fonte: Autores (2020).

Para a apresentação dos resultados e posterior análise, foram elaborados dois quadros, conforme apresentação abaixo, a saber: o primeiro contém o ano de publicação, os periódicos, a identificação dos autores e suas origens, e o segundo possui o objeto/tema, a tipificação do estudo, o objeto de análise, os resultados e ou comentários.

\section{Resultados}

A busca dos artigos selecionados proporcionou uma visão da utilização da fotografia como fonte de pesquisa na História da Enfermagem que segue demonstrada nos quadros 2 e 3.

Quadro 2: Apresentação dos artigos segundo o ano de publicação, o periódico em que foi publicado, os autores e as origens dos autores. Rio de Janeiro, RJ, Brasil, 2020.

\begin{tabular}{|c|c|c|c|}
\hline Ano de publicação & Periódico & Autores & Origem dos autores \\
\hline 2005 & $\begin{array}{l}\text { Revista Escola de } \\
\text { Enfermagem Universidade } \\
\text { de São Paulo (USP) }\end{array}$ & $\begin{array}{l}\text { 1.Bernardes, M. M. R. } \\
\text { 2. Lopes, G. T. } \\
\text { 3.Santos, T. C. F }\end{array}$ & $\begin{array}{c}1 \text { e 2. Faculdade de Enfermagem da Universidade } \\
\text { do Estado do Rio de Janeiro (FACENF/UERJ) } \\
\text { 3. EEAN }\end{array}$ \\
\hline 2005 & $\begin{array}{l}\text { Texto Contexto } \\
\text { Enfermagem }\end{array}$ & $\begin{array}{l}\text { 1.Bernardes, M. M. R. } \\
\text { 2.Lopes, G. T. } \\
\text { 3.Santos, T. C. F. }\end{array}$ & $\begin{array}{c}\text { 1.Hospital de Emergência Henrique Sérgio Gregori - } \\
\text { Resende. Universidade Estácio de Sá (UNESA) } \\
\text { 2.FACENF/UERJ } \\
\text { 3.EEAN }\end{array}$ \\
\hline 2007 & $\begin{array}{c}\text { Revista Brasileira de } \\
\text { Enfermagem (REBEn) }\end{array}$ & $\begin{array}{l}\text { 1.Bernardes, M. M. R. } \\
\text { 2.Lopes, G. T. }\end{array}$ & $\begin{array}{c}\text { 1.FACENF/UERJ e UNESA } \\
\text { 2. FACENF/UERJ }\end{array}$ \\
\hline 2009 & $\begin{array}{l}\text { Texto Contexto } \\
\text { Enfermagem. }\end{array}$ & $\begin{array}{c}\text { 1.Oliveira, A. B. } \\
\text { 2.Santos, T. C. F. } \\
\text { 3.Barreira, I. A. } \\
\text { 4.Almeida Filho, A. J. } \\
\text { 5.Lopes, G. T. } \\
\text { 6.Amorim, W. M. }\end{array}$ & $\begin{array}{c}\text { 1,2,3 e 4. EEAN } \\
\text { 5. FACENF/UERJ } \\
\text { 6. Escola de Enfermagem Alfredo Pinto da } \\
\text { Universidade Federal do Estado do Rio de Janeiro } \\
\text { (EEAP/UNIRIO) }\end{array}$ \\
\hline 2010 & $\begin{array}{c}\text { Esc Anna Nery Rev } \\
\text { Enfermagem }\end{array}$ & $\begin{array}{l}\text { 1.Oliveira, A. B. } \\
\text { 2.Santos, T. C. F. }\end{array}$ & 1 e 2. EEAN \\
\hline 2012 & $\begin{array}{l}\text { Brazilian Journal of } \\
\text { Nursing on-line }\end{array}$ & $\begin{array}{l}\text { 1.Neto, M. } \\
\text { 2.Porto, F. R. } \\
\text { 3. Aguiar, S. }\end{array}$ & $\begin{array}{l}\text { 1.Maternidade Maria Amélia Buarque de Hollanda } \\
\text { 2. EEAP/UNIRIO } \\
\text { 3.Conselho Regional de Enfermagem do Rio de } \\
\text { Janeiro (COREN) }\end{array}$ \\
\hline
\end{tabular}




\begin{tabular}{|c|c|c|c|}
\hline 2012 & $\begin{array}{c}\text { Revista Cuidado é } \\
\text { Fundamental } \text { on-line }\end{array}$ & $\begin{array}{c}\text { 1. Porto, F. R. } \\
\text { 2.Veraldo, T. X. }\end{array}$ & 1 e 2. EEAP/UNIRIO \\
\hline 2018 & História da Enfermagem: & 1. Oliveira, N.L. & 2. Silva, G.T.R. \\
& Revista eletrônica - HERE & 1 e 2. Escola de Enfermagem da Universidade \\
\end{tabular}

Fonte: Autores (2020).

$\mathrm{Na}$ descrição no quadro 2, dentre os oito artigos selecionados em periódicos indexados para o estudo, dois foram publicados no ano de 2005; um, em 2007; um, em 2009; um, em 2010; dois, em 2012 e um, em 2018. Quanto aos periódicos de publicação, observa-se que um ocorreu na Revista da Escola de Enfermagem da USP; um, na Brazilian Journal of Nursing online; um, na Revista de Enfermagem da Escola Anna Nery; dois, na Texto Contexto Enfermagem; um, na Revista Brasileira de Enfermagem; um, na HERE e um, na Revista Cuidado é Fundamental on-line. O número total de autores é de 23 e eles estão distribuídos nas seguintes instituições: nove na EEAN/UFRJ; seis na FACENF/UERJ; quatro na EEAP/UNIRIO; um na UNESA; um na Escola de Enfermagem da UFBA; um na Maternidade Maria Amélia Buarque de Hollanda e um no COREN. Nota-se que a maioria dos autores tem sua origem no Rio de Janeiro.

No quadro 3, apresentam-se o tema, a tipificação do estudo, o objeto de análise e os resultados do panorama dos artigos publicados referente à utilização das fontes históricas, com a contextualização da importância da fotografia enquanto elemento de pesquisa.

Quadro 3: Apresentação dos artigos segundo o tema, a tipificação do estudo, a utilização da fotografia como fonte histórica e os resultados. Rio de Janeiro, RJ, Brasil, 2020.

\begin{tabular}{|c|c|c|c|}
\hline Tema & $\begin{array}{c}\text { Tipificação do } \\
\text { estudo }\end{array}$ & Objeto de análise & Resultados/Comentários \\
\hline $\begin{array}{c}\text { Atuação das enfermeiras do } \\
\text { Exército inseridas na Força } \\
\text { Expedicionária Brasileira (FEB) } \\
\text { durante a } 2^{\text {a }} \text { Guerra Mundial. }\end{array}$ & Histórico-social & $\begin{array}{l}\text { Foi utilizada uma fotografia da época do } \\
\text { estudo articulada aos depoimentos orais. } \\
\text { Foi o elemento preferencial de análise. } \\
\text { O método de pesquisa foi o Analítico } \\
\text { Fotográfico Oral, criado pelos autores. }\end{array}$ & $\begin{array}{l}\text { Por meio dessa fotografia, foi possível } \\
\text { analisar que o texto fotográfico dá } \\
\text { visibilidade à atuação conjunta das } \\
\text { enfermeiras brasileiras e norte-americanas } \\
\text { no atendimento ao ferido, no cenário da } 2^{\text {a }} \\
\text { Guerra Mundial. }\end{array}$ \\
\hline $\begin{array}{l}\text { Análise semiótica em fac- } \\
\text { símiles nos estudos que se } \\
\text { utilizam da imagem fotográfica } \\
\text { como documento de pesquisa. }\end{array}$ & $\begin{array}{c}\text { Pesquisa } \\
\text { documental }\end{array}$ & $\begin{array}{l}\text { Dois fac-símiles, publicados na Revista } \\
\text { Fon-Fon, de um rito institucional da Cruz } \\
\text { Vermelha Brasileira, com deferência a um } \\
\text { dos ex-presidentes da instituição } \\
\text { conduzido às dependências institucionais } \\
\text { pelas aspirantes/enfermeiras. } \\
\text { Foram elementos centrais da análise. } \\
\text { As imagens foram analisadas por meio da } \\
\text { matriz de análise, tendo por base a } \\
\text { semiótica dos conceitos de plano de } \\
\text { expressão e conteúdo, composta de quatro } \\
\text { itens, cujos resultados foram iluminados } \\
\text { pelas noções de rito institucional, } \\
\text { representações objetais e hexis corporal. }\end{array}$ & $\begin{array}{c}\text { Esses fac-símiles foram contextualizados } \\
\text { à imagem e articulados à noção de } \\
\text { assinatura imagética por meio dos } \\
\text { elementos simbólicos do uniforme, } \\
\text { véu/gorro e símbolo da cruz } \\
\text { correspondentes à Cruz Vermelha } \\
\text { Brasileira. }\end{array}$ \\
\hline
\end{tabular}




\begin{tabular}{|c|c|c|c|}
\hline $\begin{array}{l}\text { Os efeitos simbólicos do ritual } \\
\text { de concessão da Medalha de } \\
\text { Campanha pelo Exército às } \\
\text { enfermeiras que atuaram no } \\
\text { Serviço de Saúde da Força } \\
\text { Expedicionária Brasileira } \\
\text { durante a } 2^{\text {a }} \text { Guerra Mundial. }\end{array}$ & Histórico-social & $\begin{array}{l}\text { Um registro fotográfico da concessão da } \\
\text { Medalha de Campanha às enfermeiras } \\
\text { articulado aos documentos escritos. } \\
\text { A fotografia foi o elemento preferencial } \\
\text { de análise. }\end{array}$ & $\begin{array}{l}\text { A foto, ao lado de outras fontes primárias, } \\
\text { permitiu evidenciar que a presença de } \\
\text { enfermeiras em um espaço misógino, para } \\
\text { receber medalha de honra, consagrou sua } \\
\text { aparição em um espaço público } \\
\text { tradicionalmente ocupado por homens, } \\
\text { contribuindo para a divulgação da } \\
\text { imagem da enfermeira militar. }\end{array}$ \\
\hline $\begin{array}{l}\text { Mobilização e desmobilização } \\
\text { das enfermeiras brasileiras que } \\
\text { atuaram na } 2^{\text {a Guerra Mundial. }}\end{array}$ & Histórico-social & $\begin{array}{l}\text { Uma fotografia, pertencente ao Acervo da } \\
\text { Força Expedicionária Brasileira, associada } \\
\text { a documentos escritos e depoimento oral. } \\
\text { Não foi elemento central, mas a sua } \\
\text { análise foi associada às demais fontes, } \\
\text { porém, de expressividade na comprovação } \\
\text { do reconhecimento da participação das } \\
\text { mulheres na FEB. }\end{array}$ & $\begin{array}{l}\text { A fotografia utilizada neste estudo foi } \\
\text { eficiente na comprovação do } \\
\text { reconhecimento da participação das } \\
\text { mulheres na FEB para atuarem na } \\
\text { Segunda Guerra Mundial e lhe conferiram } \\
\text { visibilidade social angariada pelo grupo. }\end{array}$ \\
\hline $\begin{array}{c}\text { Desafios enfrentados pelas } \\
\text { Enfermeiras do Transporte } \\
\text { Aéreo do Exército Brasileiro, } \\
\text { inseridas na FEB, no Teatro de } \\
\text { Operações da } 2^{\text {a Guerra }} \\
\text { Mundial. }\end{array}$ & Histórico-social & $\begin{array}{l}\text { Uma fotografia da época articulada aos } \\
\text { depoimentos de enfermeiras que } \\
\text { estiveram no conflito. Elemento } \\
\text { preferencial do estudo. O método de } \\
\text { análise foi o Analítico Fotográfico Oral, } \\
\text { criado pelos autores. }\end{array}$ & $\begin{array}{c}\text { A leitura e a interpretação do texto } \\
\text { fotográfico possibilitaram atestar e } \\
\text { conhecer a atuação dessas enfermeiras e } \\
\text { dar visibilidade ao seu trabalho no } \\
\text { atendimento aos feridos transportados nas } \\
\text { aeronaves militares, no cenário da } 2^{\mathrm{a}} \\
\text { Guerra Mundial. }\end{array}$ \\
\hline $\begin{array}{l}\text { Analisar o contexto político, a } \\
\text { base de sustentação militar no } \\
\text { Brasil e a utilização da imagem } \\
\text { feminina das enfermeiras do } \\
\text { Exército naquele período. }\end{array}$ & Histórico-social & $\begin{array}{l}\text { Uma fotografia e depoimentos orais de } \\
\text { agentes que participaram do conflito e } \\
\text { viveram os acontecimentos do recorte } \\
\text { temporal. Elemento preferencial do } \\
\text { estudo. } \\
\text { O método de análise foi o Analítico } \\
\text { Fotográfico Oral, criado pelos autores. }\end{array}$ & 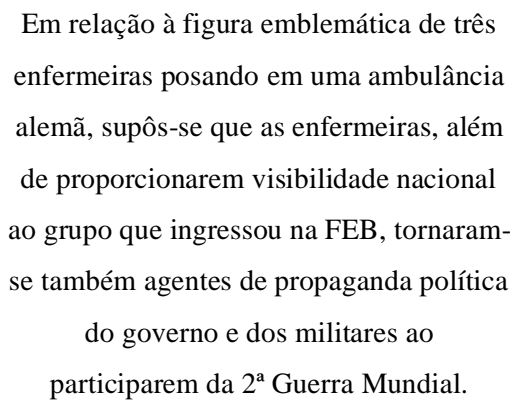 \\
\hline $\begin{array}{c}\text { Aparelhagem da imagem } \\
\text { pública da enfermeira na revista } \\
\text { Fon-Fon (1916-1931). }\end{array}$ & $\begin{array}{l}\text { Histórico- } \\
\text { exploratório }\end{array}$ & $\begin{array}{l}\text { Fac-símiles de enfermeiras, ou nelas } \\
\text { inspirados, publicados na } \\
\text { Revista Fon-Fon, no período de 1916- } \\
\qquad 1931 \text {. } \\
\text { As imagens foram analisadas por meio da } \\
\text { matriz de análise para a iconografia por } \\
\text { cronologia interna, tendo por base a } \\
\text { semiótica dos conceitos de plano de } \\
\text { expressão e conteúdo. }\end{array}$ & $\begin{array}{c}\text { No período estudado, a Revista Fon-Fon } \\
\text { veiculou } 170 \text { fac-símiles, sendo o ano de } \\
1922 \text { com maior veiculação e o eixo } \\
\text { Propagandas com o maior quantitativo. } \\
\text { Pode-se inferir que a veiculação de } \\
\text { imagens de enfermeiras, ou nelas } \\
\text { inspiradas, colabora na construção da } \\
\text { identidade profissional da enfermeira. }\end{array}$ \\
\hline $\begin{array}{c}\text { Biografia de Maria José de } \\
\text { Oliveira e suas contribuições } \\
\text { para o desenvolvimento da } \\
\text { Escola de Enfermagem da } \\
\text { Universidade Federal da Bahia. }\end{array}$ & $\begin{array}{l}\text { Pesquisa } \\
\text { descritiva e } \\
\text { histórica. }\end{array}$ & $\begin{array}{l}\text { As fotografias foram utilizadas em } \\
\text { conjunto com as demais fontes escritas de } \\
\text { modo que mantiveram o grau de } \\
\text { importância. }\end{array}$ & $\begin{array}{l}\text { As fotografias foram utilizadas para } \\
\text { retratar as diferentes fases da trajetória } \\
\text { histórica de Maria José de Oliveira à } \\
\text { medida que elas iam sendo descritas. }\end{array}$ \\
\hline
\end{tabular}


Fonte: Autores (2020).

Apreendem-se, pelo exposto no quadro 3, as seguintes considerações: o tema prevalente discorre sobre a história das mulheres na Enfermagem, seja nas Guerras Mundiais, seja a imagem pública da enfermeira ou mesmo o estudo de imagens fotográficas veiculadas em meios de comunicação que as retratavam, reiterando a prevalência das mulheres na profissão. A tipificação do estudo mais recorrente foi a abordagem sócio-histórica, seguida da pesquisa documental e histórico-exploratória, mantendo a coerência com os estudos históricos para o seu desenvolvimento.

Destacam-se, dentre os artigos, o uso da análise semiótica em dois fac-símiles e os tipos de abordagens utilizadas pelos autores para a elaboração das produções científicas, que foram os quantitativos e qualitativos. A retratação das enfermeiras e/ou das aspirantes à enfermeira da Escola Prática de Enfermeiras da Cruz Vermelha Brasileira (CVB) e do general Thaumaturgo de Azevedo foi realizada pela CVB em seu rito institucional de homenagem, no período histórico da Primeira Guerra Mundial. A construção da imagem da enfermeira no Brasil, com a contribuição da Revista Fon-Fon, envolveu o contexto sociopolítico entre janeiro de 1916 e dezembro de 1923, que foi marcado pelos últimos anos da Primeira Guerra Mundial. Há o registro da profissionalização da Enfermagem e da biografia de Maria José de Oliveira com as contribuições, as lutas, durante a sua vida em prol da Enfermagem, o reconhecimento como figura importante no grupo social e o destaque na profissão.

\section{Discussão}

A utilização da fotografia como fonte de pesquisa na Enfermagem é recente e data de poucos anos, se comparada a outros tipos de fontes, tanto que os trabalhos detectados foram publicados recentemente, com a demonstração que só atualmente os pesquisadores em História da Enfermagem passaram a utilizar-se desta fonte. A fotografia começou a ser utilizada no campo das Ciências Sociais a partir de 1980, com o redimensionamento das técnicas dominantes desse campo científico (Rios, Costa \& Mendes, 2016).

No que diz respeito à autoria dos estudos, observa-se que, em sua totalidade, foram realizados por enfermeiros brasileiros, comprovando o crescimento do interesse e a valorização pelas pesquisas sobre a história da profissão. É crucial que os enfermeiros se apropriem da temática e discutam, de forma problematizadora, a retratação da História da Enfermagem a fim de tomar conhecimento do passado para compreender o presente e melhor direcionar o futuro (Padilha \& Borenstein, 2006).

O uso da fotografia como método de pesquisa até o momento está restrito a um grupo seleto de pesquisadores, em sua maioria, de instituições públicas concentradas na região Sudeste, especialmente na cidade do Rio de Janeiro. Para entender o porquê dessa centralização, deve-se analisar o contexto histórico e demográfico: o Sudeste tem o maior contingente populacional de enfermeiros e grande investimento no aumento de instituições de cursos de graduação e pós-graduação em Enfermagem, além de ter, dentro de suas delimitações, duas grandes metrópoles com produção expressiva no campo da pesquisa (Marinho, Paz, Jomar \& Abreu, 2019).

Destaca-se, no Rio de Janeiro, a Escola de Enfermagem Anna Nery, primeira escola sobre o modelo nigthgeliano, e somam-se a essa a Escola de Enfermagem Alfredo Pinto, da Universidade Federal do Estado do Rio de Janeiro, a Universidade Federal Fluminense e a Faculdade de Enfermagem da Universidade do Estado do Rio de Janeiro, produtoras de conhecimento.

A região Sudeste concentra instituições de Ensino Superior relacionadas ao campo da história, como, por exemplo, os museus importantes. Para a Enfermagem, não é diferente. Há, nessa região, os Centros de Memórias, além do Museu da Escola de Enfermagem Anna Nery e o Museu da Escola de Enfermagem de Ribeirão Preto, o que evidencia o número elevado de escritores na região. Por outro lado, verifica-se que um dos trabalhos foi publicado por pesquisadores oriundos da Bahia, especificamente da Escola de Enfermagem da Universidade Federal da Bahia, o que remete à existência do Museu Nacional da Enfermagem localizado em Salvador. 
Na abordagem sobre a história das mulheres na Enfermagem, seja nas Guerras Mundiais, seja na imagem pública da enfermeira ou mesmo no estudo de imagens fotográficas veiculadas em meios de comunicação, as quais retratam a época estudada, a profissão era predominantemente feminina. Cada objeto estudado tem a sua singularidade, revelando as condições difíceis que as enfermeiras brasileiras desde então tiveram que enfrentar e ainda enfrentam. A Segunda Guerra Mundial é marcada pelas especificidades da criação do Quadro de Enfermeiras da Reserva do Exército, pelo Decreto-Lei $\mathrm{n}^{\circ}$ 6.097/1943, em que as voluntárias de todas as partes do país, solteiras, viúvas e casadas, e com os cursos mais diversos na área de Enfermagem, acorreram à convocação para realizar o Curso de Emergência de Exército (Oliveira, 2012).

Fatores como o impacto mundial e a repercussão na construção do presente e a preparação diferenciada das enfermeiras em comparação ao habitus profissional da Enfermagem na época, ao terem formação militar e diferenciada experiência, faziam parte das equipes multidisciplinares de diversos lugares do mundo (Bernardes, Lopes \& Santos, 2005). Cabe aqui registrar a força da simbologia no recebimento de medalha por honraria. Esse recebimento é pela enfermeira estar em espaço misógino, o que contribuiu para a construção da imagem da enfermeira militar e a conquista de um espaço que é considerado de maioria masculina (Oliveira \& Santos, 2010).

Os desafios enfrentados por essas enfermeiras militares eram elevados e os treinamentos específicos objetivavam atender às necessidades dos pacientes e obter a qualificação para elas estarem em diversas situações com diferentes fatores estressantes que rodeavam o cuidado em meio à guerra, que eram constantes (Bernardes \& Lopes, 2007). O fator que auxiliava a preparação dessas enfermeiras eram a experiência que tinham e a possibilidade de utilização de algumas tecnologias estrangeiras, como exemplo, ambulâncias alemãs utilizadas no cenário da guerra, o que despertava o interesse de estudiosos (Bernardes, Lopes \& Santos, 2005).

De tal modo, a análise da fotografia, articulada com os depoimentos orais e os documentos escritos, mostra que a atuação dessas enfermeiras ampliou as possibilidades femininas no espaço público, posto que perdurava a ideia de que, geralmente, os homens deveriam ser destinados para as frentes de batalha, e as mulheres, geralmente, ficavam em casa cuidando dos filhos e, por extensão, empregadas na garantia do adequado funcionamento da sociedade civil (Oliveira, Santos, Barreira, Lopes, Almeida Filho \& Amorim, 2009).

A abordagem sócio-histórica tem sido prevalente em estudos que utilizam a fotografia, pois consiste na preocupação em compreender os eventos investigados, a descrição e a procura das possíveis relações com a integração entre o individual e o social (Freitas, 2002). Entretanto, o estudo histórico-exploratório tem a finalidade de familiarizar-se com o fenômeno, para a aproximação da temática na obtenção de novas ideias em relação ao objeto, o que caracteriza a pesquisa como documental e estabelece o procedimento de coleta de dados (Sá-Silva, Almeida \& Guindani, 2009).

A pesquisa documental consiste em um procedimento que utiliza métodos e técnicas para a apreensão, a compreensão e a análise de documentos dos mais variados tipos e que não receberam nenhum tratamento científico, como relatórios, reportagens de jornais, revistas, cartas, filmes, gravações, fotografias, pinturas, entre outras matérias de divulgação (Sá-Silva, Almeida \& Guindani, 2009).

A fotografia é vista como um documento, rico em informações e significados, que coloca o pesquisador direto com um momento, um personagem e uma época. Desse modo, torna-se relevante inserir a fotografia como fonte de conhecimento histórico (Silva, Mello \& Santos, 2016).

Este documento, a fotografia, é a técnica de escolha para a criação de documentos imagéticos bidimensionais, por meio da captação passiva de luz e outras radiações eletromagnéticas refletidas, o que permite a captação total de todos os elementos do momento. Desse modo, é notória a possibilidade da realização de estudos com a utilização da fotografia como base, tendo em vista que, durante a sua criação, não são perdidos elementos primordiais, com a possibilidade de posteriormente realizar 
o seu estudo de forma clara, o que permite estudar o passado e apresentar um rico leque de detalhes não conseguido com a mesma clareza quando utilizados outros tipos de documento (Silva, Mützenberg \& Cisneiros, 2012).

A análise das fotografias utilizadas nas suas respectivas pesquisas deve ser feita a partir da metodologia e da delimitação do objeto que está sendo investigado. Dado o exposto, na análise iconológica, o pesquisador deve adentrar o contexto da imagem com a interpretação de todas as informações anexas, como: o espaço; o tempo histórico; o fotógrafo; a tecnologia utilizada; os itens e os indivíduos que aparecem na iconografia, entre outros (Schvambach, 2008).

Nota-se uma pluralidade de fontes utilizadas nos artigos selecionados, porém, há a presença da mesma fonte em mais de um artigo, como a Revista Fon-Fon e o acervo da FEB, reforçando temáticas com o envolvimento de cerimoniais da Enfermagem e do militarismo, que são os assuntos mais abordados nos estudos em História da Enfermagem, quando se trata do uso da fotografia. As fotografias, em sua maioria, foram retiradas de acervos pessoais, revistas, jornais e propagandas das épocas retratadas. Acrescenta-se, ainda, que existem ricos acervos contendo fotografias, documentos e artefatos históricos da época em questão, como no Arquivo Histórico do Exército, além dos Centros de Documentação vinculados principalmente às instituições de Ensino Superior localizadas no Rio de Janeiro, que viabilizam pesquisas dessa natureza.

Para a análise crítica das fontes e a observação documental na metodologia historiográfica, é recomendada a obrigatória apuração da credibilidade e da representatividade do material (Padilha, Bellaguarda, Nelson, Maia \& Costa, 2017). Destaca-se que as fotografias foram elementos centrais e ou preferenciais de análise com evidência explícita da adequabilidade das fotografias ao tema e a articulação da imagem com outras fontes utilizadas para a pesquisa, tais como os documentos escritos e a história oral, o que ratifica o contexto, o conteúdo da imagem para a validação das informações contidas na fotografia.

Com isso, a fotografia pode gerar diferentes conclusões e questionamentos por ser polissêmica, para a obtenção da consistência dos fatos pesquisados, do uso de outras fontes para a validação da ideia obtida, a partir da análise da imagem que se faz relevante para as confirmações de análises pré-existentes, a ampliação dos dados coletados e o aprofundamento na temática estudada (Manini, 2002).

Por sua vez, a articulação entre o texto fotográfico e os depoimentos orais favoreceu a interpretação dos dados na busca do estabelecimento dos nexos com o contexto político-social; a descrição do motivo; a data; o cenário; os agentes; a "habitalidade" do espaço; a representação do espaço e a encenação que a foto encerrava (Oliveira \& Santos, 2010).

No tocante ao processamento das fontes, os artigos demonstraram a diversidade de seus métodos, destacando-se a utilização da base teórica da semiótica. Segundo Augusto (2016), a análise semiótica vai além do estudo dos signos, pois também é uma teoria da comunicação, sendo o signo um mediador entre o objeto e o interpretante. Como a maior parte das imagens dos artigos aqui utilizados está em preto e branco, a fotografia ganha ainda uma outra característica: torna-se um símbolo, gerando espaço interpretativo e subjetivo pela ausência de cores. Os conceitos da semiótica incluem os planos de expressão e conteúdo. A expressão refere-se à manifestação desse conteúdo como um sistema de significação verbal, não verbal ou sincrético, enquanto o conteúdo corresponde ao significado do texto, ou seja, o que o texto relata e como ele faz para dizer o que diz (Neto, Porto \& Aguiar, 2012). A partir dos planos de expressão e conteúdo, foi aplicada, às imagens, uma matriz de análise, composta pelos seguintes itens: dados de identificação das iconografias; o plano de expressão; o plano do conteúdo e, finalmente, os dados complementares obtidos em outras imagens. A análise fotográfica deve ir além da leitura de seus sentidos denotativos e subjetivos, compreendendo as suas características em totalidade, como a composição da imagem (temática, contexto e informações técnicas, visuais e escritas), o produtor (fotógrafo) e os seus possíveis receptores (Rodrigues, 2007).

Os autores dos artigos em estudo criaram o método analítico fotográfico oral, que possibilita, ao pesquisador, abordar e aprofundar, por diferentes técnicas, o conhecimento sobre um determinado fenômeno em estudo na pesquisa histórica, que pode advir da articulação do texto fotográfico com os depoimentos e os documentos. Esses procedimentos, empregados na busca 
e na análise das informações, vislumbraram uma nova maneira de revitalização da memória durante a entrevista (Bernardes \& Lopes, 2007).

A utilização do método da história oral de vida foi importante para compreender o sujeito como indivíduo único e singular na história. Sua aplicação é passível de reprodutibilidade para escrever novas biografias. E a análise pela técnica de Análise de Conteúdo Temática tornou possível discorrer a narrativa a partir da organização de eixos temáticos que contemplaram a vida social e profissional da biografada em questão. Entretanto, as fotografias foram utilizadas, neste caso, de forma ilustrativa, retratando as diferentes fases de sua trajetória histórica.

No espaço social (civil), a visibilidade em questão, expressa pelas fotografias analisadas dos elementos simbólicos, que contribuíram para a construção da imagem da enfermeira, por meio do uniforme e seus adereços simbólicos, véu/gorro e símbolo da cruz, na composição para a distinção de uma assinatura imagética, é utilizada, muitas vezes, de acordo com o jogo de interesse presente no contexto histórico de cada época (Neto, Porto \& Aguiar, 2012).

$\mathrm{Na}$ esteira do espaço social (civil), o auge da visibilidade aos seus pares encontra-se ancorado na biografia da enfermeira Maria José de Oliveira, ao demonstrar a exemplaridade profissional, conferindo-lhe uma importância diferenciada, distinta e individual (Oliveira \& Silva, 2018).

Na condição de enfermeiras militares, ao tempo em que se representou a ocupação de um espaço homologado por mandatários do poder, também contribuiu para consagrar a inserção de mulheres em espaços públicos consagrados aos homens, ainda que na retaguarda (Oliveira, Santos, Barreira, Lopes, Almeida Filho \& Amorim, 2009).

A identidade profissional da Enfermagem é percebida decorrente dos contextos históricos que originaram mudanças políticas, sociais, econômicas e culturais à época, possibilitando o movimento das mulheres em direção aos processos de socialização. A identidade é o resultado a um só tempo estável e provisório, individual e coletivo, subjetivo e objetivo, biográfico e estrutural, dos diversos processos de socialização que, conjuntamente, constroem os indivíduos e definem as instituições (Dubar, 2005).

Depreende-se que essa identidade foi alcançada quando se observou o trabalho dessas mulheres em que as suas ações contribuíram para o crescimento da sociedade, o que diz que essa classe é elemento fundamental para o pleno desenvolvimento civil. Época em que a profissão não possuía visibilidade, porém, as pessoas retratadas mostraram que estavam prontas para assumir um papel de destaque na sociedade. Uma identidade profissional bem estruturada auxilia no alcance da notoriedade e credibilidade de um indivíduo perante o meio em que está inserido, contribuindo significativamente para o desenvolvimento de sua carreira.

A conquista da identidade faz-se, assim, necessária, pois indica a maneira como as pessoas gostariam de ser percebidas. Os elementos simbólicos, que representam a Enfermagem, contribuem para a sua visibilidade, criando, assim, uma identidade própria, que não deve ser confundida. Os elementos simbólicos apresentados contribuíram para o desvelamento de alguns dos códigos institucionais, que tangenciam a construção da imagem da enfermeira (Neto, Porto \& Aguiar, 2012).

\section{Conclusão}

O conhecimento histórico faz-se essencial para o entendimento e a construção do presente da Enfermagem. Dito isso, a compreensão da história da evolução da fotografia, sua inserção como fonte de estudo no meio científico, inclusive nas Ciências Sociais, na História da Enfermagem e seu uso como fonte em pesquisas na área são indispensáveis para a elaboração de análises dos dados coletados acerca do uso da fotografia.

A análise possibilitou apreender o conhecimento presente na literatura escrita por enfermeiros que utilizaram a fotografia como fonte nos seus estudos históricos de Enfermagem. Assim, evidenciaram-se a notoriedade do uso da fonte 
fotográfica e as diversas possibilidades de sua utilização em pesquisas dos mais diversos eixos e temáticas dentro do contexto histórico da Enfermagem.

O uso de arquivos fotográficos permitiu descobrir a visão da sociedade para com a Enfermagem da época, assim como evidenciar a identidade forjada necessária para cada ocasião em que a Enfermagem foi chamada a atuar. Observaram-se um seleto número de autores e os artigos publicados que utilizaram a fotografia como fonte de pesquisa na História da Enfermagem e o seu uso entre os pesquisadores da História da Enfermagem, bem como a centralização dessas publicações em instituições públicas concentradas no Sudeste do país. Além desses fatores, os eventos conflituosos, com destaque para a Segunda Guerra Mundial, são temas recorrentes entre os artigos selecionados.

A abordagem utilizada é a sócio-histórica e os estudos possuem em comum as discussões acerca da visibilidade e da identidade profissional da época estudada. A fotografia articula-se com outras fontes para qualificar o desenvolvimento e o aprofundamento da pesquisa no que diz respeito à contextualização dos fatos.

Compreende-se que os investimentos devem ser feitos para que a História da Enfermagem seja explorada e contemplada com novos estudos e novos pesquisadores. $\mathrm{O}$ uso de diferentes fontes, inclusive a fotografia, deve ser aproveitado para que o conhecimento construído seja o mais fundamentado e explorado possível. A história vive e cabe aos pesquisadores desbravar, reconhecer e utilizar esta técnica.

Cabe aqui registrar que os incentivos e os investimentos na produção de estudos na área da História da Enfermagem devem ser feitos tendo em vista que há um campo rico para possíveis problematizações; necessita-se de exploração da memória e dos artefatos históricos com aprofundamento; precisam-se realizar novos estudos com a fotografia, com novos pesquisadores, para que haja produção de conhecimento com a utilização desta fonte.

\section{Referências}

Academia Brasileira de História da Enfermagem - ABRADHENF (2018). Home. de http://www.abradhenf.com.br.

Bernardes, M. R.; Lopes, G. T., \& Santos, T. C. F. (2005). A visibilidade da atuação de uma enfermeira do Exército Brasileiro a um ferido na $2^{\mathrm{a}}$ Guerra Mundial. Revista da Escola de Enfermagem da USP, 39(1), 62-67. http://www.scielo.br/ https://doi.org/10.1590/S0080-62342005000100008.

Bernardes, M. M. R., \& Lopes, T. (2007). Enfermeiras do Exército Brasileiro no transporte aéreo de feridos: um desafio enfrentado na $2^{\text {a }}$ Guerra Mundial. Revista Brasileira de Enfermagem, 60(1), 68-72. de http://www.scielo.br https://doi.org/10.1590/S0034-71672007000100012.

Bernardes, M. M. R.; Lopes, G. T., \& Santos, T. C. F. (2005). Base de sustentação militar de Vargas durante a $2^{\mathrm{a}}$ Guerra e a soberania bélica alemã: percepções de enfermeiras e militares. Texto \& Contexto - Enfermagem, 14(4), 544-550. de http://www.scielo.br/. https://dx.doi.org/10.1590/S0104-07072005000400011.

Camargo, R. A.; Luchesi, L. B.; Porto, F.; Neto, M.; Mazziero, A. S., \& Lima, C. C. C. A. (2020). Tarsila do Amaral e Glete de Alcântara: história em arte e fotografia. Revista Brasileira de Enfermagem, 73(2), e20170839. http://www.scielo.br/ . https://dx.doi.org/10.1590/0034-7167-2017-0839.

Dubar, C. (2005). A socialização. Construção de identidades sociais e profissionais. Martins Fontes. São Paulo.

Escola de Enfermagem de Ribeirão Preto (EERP) (2018). Acervo. São Paulo. http://www.eerp.usp.br

Felizardo, A., \& Samain, E. (2007). A fotografia como objeto e recurso de memória. Revista Discursos Fotográficos, Londrina, v. 3 , n. 3, p. $205-220,2007$. http://www.uel.br/revistas/uel/index.php/discursosfotograficos/article/view/1500/1246. http://dx.doi.org/10.5433/1984-7939.2007v3n3p205.

Freitas, M. T. A. (2002). A abordagem sócio-histórica como orientadora da pesquisa qualitativa. Cadernos de Pesquisa, (116), 21-39. http://www.scielo.br https://dx.doi.org/10.1590/S0100-15742002000200002

Kossoy, B. (2001). Fotografia e História. 2. ed. rev. São Paulo: Ateliê Editorial.

Manini, M. P. (2002). Análise documentária de fotografias: um referencial de leitura de imagens fotográficas para fins documentários. Tese (Doutorado). São Paulo: Escola de Comunicações e Artes, USP.

Marinho, G. L; Paz, E. P. A.; Jomar, R. T., \& Abreu, A. M. M. (2019). Enfermeiros no Brasil: transformações socioeconômicas no início do século XXI. Escola Anna Nery, 23(1), e20180198. http://www.scielo.br/scielo.php?script=sci_arttext\&pid=S1414-81452019000100215\&lng=en\&nrm=iso. https://doi.org/10.1590/2177-9465-ean-2018-0198.

Neto, M.; Porto, F., \& Aguiar, S. (2012). Aplicação da semiótica na análise de fac-símiles: pesquisa documental. Online Brazilian Journal of Nursing, 11 (3):84864. de http://www.objnursing.uff.br/index.php/nursing/article/viewFile/3705/pdf. 
Oliveira, A. B.; Santos, T. C. F.; Barreira, I. A.; Lopes, G. T.; Almeida Filho, A. J., \& Amorim, W. M. (2009). Enfermeiras brasileiras na retaguarda da Segunda Guerra Mundial: repercussões dessa participação. Texto \& Contexto - Enfermagem, 18(4), 688-696.://www.scielo.br/scielo.php?script=sci_arttext\&pid=S010407072009000400010\&lng=pt\&nrm=iso. https://doi.org/10.1590/S0104-07072009000400010.

Oliveira, A. B. (2012). Enfermeiras da força expedicionária brasileira no front do pós-guerra: o processo de reinclusão no serviço militar ativo do exército (1945-1957) (Tese de doutorado). Escola de Enfermagem Anna Nery - EEAN, Rio de Janeiro, RJ, Brasil.

Oliveira, A. B., \& Santos, T. C. F. (2010). Condecorações de guerra como investidura de bens simbólicos às ex-enfermeiras febianas. Escola Anna Nery, 14(1), 1-2. http://www.scielo.br/scielo.php?script=sci_arttext\&pid=S1414-81452010000100004\&lng=pt\&nrm=iso. https://doi.org/10.1590/S141481452010000100004 .

Oliveira, N. L., \& Silva, G. T. R. (2018). Maria José de Oliveira: trajetória de vida e contribuições da identidade profissional de enfermeira na Bahia. História enfermagem Revista eletrônica, 9 (1):61-75. http://here.abennacional.org.br/here/v9/n1/a5.pdf.

Padilha, M. I. C. S., \& Borenstein, M. S. (2006). História da Enfermagem: ensino, pesquisa e interdisciplinaridade. Escola Anna Nery, 10(3), 532-538. http://www.scielo.br/scielo.php?script=sci_arttext\&pid=S1414-81452006000300024\&lng=pt\&nrm=iso. https://doi.org/10.1590/S1414-81452006000300024.

Padilha, M. I.; Bellaguarda, M. L. R.; Nelson, S.; Maia, A. R. C., \& Costa, R. (2017). O Uso das Fontes na Condução da Pesquisa Histórica. Texto \& Contexto Enfermagem, 26(4), e2760017. http://www.scielo.br/scielo.php?script=sci_arttext\&pid=S0104-07072017000400605\&lng=pt\&nrm=iso. https://doi.org/10.1590/0104-07072017002760017.

Rios, S. O.; Costa, J. M. A., \& Mendes, V. L. P. S. (2016). A fotografia como técnica e objeto de estudo na pesquisa qualitativa. Revista Discursos Fotográficos, Londrina, v. 12, n. 20, p. 98-120. http://www.uel.br/revistas/uel/index.php/discursosfotograficos/article/view/22542. http://doi.org/10.5433/1984$7939.2016 \mathrm{v} 12 \mathrm{n} 20 \mathrm{p} 98$.

Sá-Silva, J. R.; Almeida, C. D., \& Guindani, J. F. (2009). Pesquisa documental: pistas teóricas e metodológicas. Revista Brasileira de História \& Ciências Sociais, n. 1. https://www.rbhcs.com/rbhcs/article/view/6/pdf.

Silva, D. A.; Mello, N. D. \& Santos, K. A. (2016). Uso da fotografia documental como fonte histórica. Revista Educação UNG Ser, 67-69.

Schvambach, J. (2008). A fotografia como fonte de pesquisa e sua ficção documental. Editora e Gráfica Universitária da UFPEL. Pelotas. https://www.unochapeco.edu.br/static/data/portal/downloads/2544.pdf

Silva, S. F. S. M.; Mützenberg, D., \& Cisneiros, D. (2012). Arqueologia visual: O uso das imagens fotográficas na produção do conhecimento arqueológico e historiografia da arqueologia. Revista Museu Arq. Etn., São Paulo, 22: 137-156.

Souza, M. T.; Silva, M. D., \& Carvalho, R. (2010). Revisão Integrativa: o que é e como fazer. Einstein, São Paulo [on-line], v. 8, n. 1, p.102-106. ISSN 16794508. http://www.scielo.br/scielo.php?script=sci_arttext\&pid=S1679-4508201000100102\&lng=en\&nrm=iso. http://dx.doi.org/10.1590/s167945082010 rw1134.

TIC/UFRJ (2017). Museu da EEAN. Rio de Janeiro: UFRJ. http://eean.ufrj.br/index.php/museu/143-museu.

Veraldo, T. X.; Porto, F., \& Moreira, A. (2010). A aparelhagem da imagem pública da enfermeira na revista Fon-Fon (1916-1923). Revista de Pesquisa: Cuidado é fundamental [on-line], 2. ed. p. 194-197. http://www.seer.unirio.br/index.php/cuidadofundamental/article/view/820. https://dx.doi.org/10.9789/21755361.2010.v0i0.\%p. 